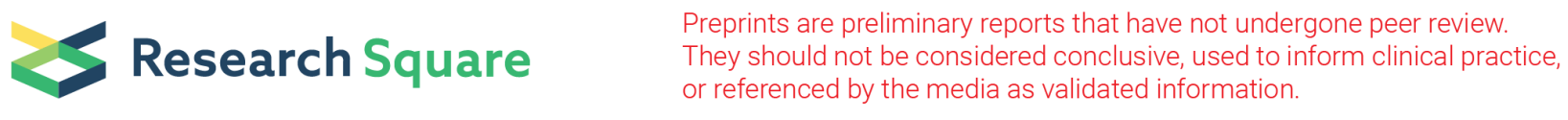

\title{
Multi-drug resistant, extended spectrum beta-lactamase and carbapenemase-producing bacterial isolates among children under five years old suspected bloodstream infection in a specialized Hospital in Ethiopia: Cross-sectional study
}

Mequanint Mitiku Tadesse

Black Lion Hospital

Zeleke Ayenew Matebie ( $\square$ zelekeayenew377@gmail.com)

Ethiopian Public Health Institute https://orcid.org/0000-0003-4216-6634

Kassu Desta Tullu

Addis Ababa University College of Health Sciences

Research article

Keywords: Bloodstream infection, multi-drug resistance, extended spectrum beta-lactamase, carbapenem resistant Enterobacteriaceae.

Posted Date: September 25th, 2019

DOI: https://doi.org/10.21203/rs.2.14952/v1

License: (c) (7) This work is licensed under a Creative Commons Attribution 4.0 International License. Read Full License 


\section{Abstract}

Background : Bloodstream infections due to bacterial pathogens are a major cause of morbidity and mortality among pediatric patients. Emergence of drug resistance in high classes of antibiotics among the bacterial pathogens is another issue of the public health concern. Therefore, this study aimed to determine Multi-drug resistant, extended spectrum $\beta$-lactamase and carbapenemase producing bacterial isolates among septicemia suspected under five Children in Tikur Anbesa Specialized Hospital, Addis Ababa Ethiopia. Methods : Across-sectional study was conducted from September 2017 to June 2018 among pediatric patients with febrile illness aged under five in Tikur Anbesa Specialized Hospital. Three hundred forty blood samples were collected and processed following standard microbiological techniques and culture was performed using BacT/Alert machine in combination with conventional method. Antimicrobial susceptibility testing of the isolates was performed by Kirby-Bauer disc diffusion method and MIC technique. Result: A total of 137(40.2\%) bacterial pathogens were isolated from 340 pediatric patients suspected of BSI with febrile illness. Of these isolates $54 \%$ were Gram negative bacteria. Among gram negative isolates 43 (31.4\%) Klebsiella pneumonia e and Acinitiobacter species were the most frequently isolated pathogens. Klebsiella pneumoniae isolates were 95.6\% MDR, 23.7\% ESBL, and 27.1\% CRE in children. Conclusion : In this study, Klebsiella pneumoniae is a common pathogens associated with $\mathrm{BSI}$ in pediatrics with high antimicrobial resistance. Extended spectrum beta-lactamase producing organisms were common in Klebsiella species and Escherichia coli isolates. Since most of isolates exhibit multidrug resistant, invitro- susceptibility of antimicrobials is mandatory. Strengthen antimicrobial surveillance system and antimicrobial stewardship is necessary for better management of antibiotics in addition to infection prevention practice in Hospital settings.

\section{Background}

Bloodstream infections are one of the major causes of morbidity and mortality globally. Roughly 200,000 cases of bacteremia occur every year with mortality rates ranging from 20 to $50 \%$ [1]. Bloodstream infection comprise $10-20 \%$ of every nosocomial disease and is the eighth leading cause of mortality in the United States with some 17\% causing death [2]. In sub Saharan nations including Ethiopia, septicemia is a significant cause of illness and death in young people with death rate approaching $53 \%$ making it a noteworthy medical issue in under-developed countries [3].

In many studies, a wide range of bacteria have been described in febrile patients including gram negative bacteria such as Escherichia coli, Pseudomonas aeruginosa, Klebsiella species, Neisseria meningitidis, Haemophilus influenzae, and gram positive bacteria such as coagulase negative staphylococci (CONS), Staphylococcus aureus, Streptococcus pneumoniae, Streptococcus pyogenes, Streptococcus agalactiae, and Enterococcus faecium. The diagnosis of these infections can be confirmed by blood culture, which is routinely available in few Hospitals in developing countries $[4,5]$.

Bacterial pathogens isolated from bloodstream infection are a major source of critical patient morbidity and mortality. The effect of explicit etiologic agents on BSI persistent have a major impact; BSI increases the death rate, causes outpatients to remain in hospital emergency, and increases the cost in providing human services [6,7].

The timely and appropriate use of antibiotics is currently the best way to treat bacteremia. However, many bacterial pathogens have become resistant to antibiotic regimens and are a serious public health concern with global economic and social implications. Antibiotic resistance is a growing problem in resource limited countries like Ethiopia. In Ethiopia, the unregulated and over-the-counter sale of antimicrobials without a prescription, mainly for self-treatment of suspected infection in humans, and to a lesser extent for use in animals inevitably leads to the emergence and rapid dissemination of resistance [8]. Many studies have found that inadequate empirical therapy of bacteremia infections are associated with adverse outcomes including increased mortality and increased emergence of drug resistance [9-10].

During the previous several decades, opposition to the use of antimicrobials has expanded, and the points of view are disturbing [11]. The proper use of antibiotics is well understood in the western world but this learning is deficient in developing African countries [12-14].Recent studies on the outcome of sepsis in Africa are almost non-existent although there are a few reports. The most concerning reports on antimicrobial resistance concern patients admitted to hospitals [15], while community- acquired infections may have lower levels of resistance [16].

In Ethiopia, the resource situation has not allowed antimicrobial resistance to be prioritized as a major public health concern despite the obvious needs [17]. The aim of this study was to identify and determine multi-drug resistant, extended spectrum $\beta$-lactamase and carbapenemase producing bacterial isolates among blood culture specimens from pediatric patients under five years of age fromTikur Anbessa Specialized Hospital using an automated BacT/Alert instrument.

\section{Methods}

\section{Study setting}


The study was conducted at the Tikur Anbesa Specialized Hospital (TASH) which is the teaching hospital for the College of Health Science at Addis Ababa University. TASH is the largest specialized hospital in Ethiopia with over 700 beds, and serves as a training center for undergraduate and postgraduate medical students, dentists, nurses, midwives, pharmacists, medical laboratory technologists, radiology technologists, and others who lead the solution for health problems of the community and the nation. With more than 70 percent of childhood deaths attributable to communicable diseases and malnutrition, Ethiopia's healthcare resources have been primarily focused on the treatment and prevention of diseases such as malaria and diarrhea [18].

\section{Study design and period}

A cross-sectional study was conducted from September 2017 to June 2018 to identify the bacterial profiles and antimicrobial susceptibility patterns among septicemia in under five patients with acute febrile illness in Tikur Anbessa Specialized Hospital in Addis Ababa.

\section{Inclusion and Exclusion criteria}

Children aged under five years including neonates with fever, those diagnosed with sepsis, severe sepsis and septic shock. All children who gave blood samples were volunteers with parental permission to participate in the study. Those patients who were a febrile under five years and patients who had taken antibiotics within the last 7 days were excluded.

\section{Sample size calculation}

The sample size for the study was determined using a single population proportion formula. The study considered prior prevalence and antibiotic resistance data in septicemia patients at Tikur Anbesa Specialized Hospital which demonstrated 27.9\% bacterial isolation (19) with a $95 \%$ level of confidence and $5 \%$ margin of error. $n=(Z a)^{2}(p q) / d^{2}$ where: $n=$ sample size, $Z a / 2=$ level of confidence, $P=$ diarrhea prevalence $q=$ $1-p d 2=$ margin of error (0.05): $n=\underline{z^{2} *} p * q / d^{2}$,

$, p=0.279, q=0.721, d=0.05, Z a / 2=1.96 ; 1.96 \underline{2} * 0.279 * 0.721 / 0.05^{2}=309$. Considering a $10 \%$ non- response rate, a total of 340 children patients were enrolled in the study.

\section{Sampling technique}

The study subjects were selected using convenient sampling technique from all patients attending Tikur Anbessa Specialized Hospital among children under five with febrile illness clinically diagnosed at pediatric OPD, ICU and inpatient pediatric wards admitted during the study period. Venipuncture was employed for those children that fulfilled the inclusion criteria.

\section{Data collection procedure}

A standardized questionnaire was used to collect socio-demographic characteristics such as, gender, age, and clinical presentation (fever, vomiting), and household income. Patients visiting outpatient departments (pediatric and general medicine) and those admitted through inpatient units were investigated for bloodstream infections by their unit physicians. Selection criteria included the onset of fever ( $>37 \circ \mathrm{C})$ or the presence of any clinical symptoms compatible with infection.

\section{Blood sample collection}

A venous blood culture specimen was taken using aseptic technique by cleansing the collection site with $70 \%$ alcohol followed by $10 \%$ povidoneiodine solution and were collected by trained laboratory personnel. About $2.5-5 \mathrm{ml}$ of blood was collected and inoculated in an aerobic $30 \mathrm{ml}$ BacT/ALERT PF Plus pediatric bottles with a blood to broth ratio of 1: 10-1:30. At least 2 sets of blood cultures were collected from a patient with suspected bacteremia prior to the initiation of antimicrobial therapy.

\section{Culture Isolation and Identification}

The initial BacT/ALERT culture bottles were incubated in automated BacT/ALERT® $3 \mathrm{D}$ instrument at $37^{\circ} \mathrm{C}$ with $5 \% \mathrm{CO}_{2}$ for 5 days for the primary isolation. Two aerobic blood culture bottles were used for each patient and growth in both bottles were considered a positive culture. Microbial growth was detected by the instrument and subsequently sub cultured on $5 \%$ sheep blood agar, chocolate agar, and MacConkey Agar plates (Oxoid Ltd, UK) and incubates for bacterial isolation at $37^{\circ} \mathrm{C}$ for $18-24$ hours. The MacConkey agar plate was incubated aerobically while chocolate and blood agar plates were incubated in a microaerophilic atmosphere $\left(5-10 \% \mathrm{CO}_{2}\right)$ using a candle jar. A negative result was checked by a gram stain and a final subculture at the end of 5th day before reporting as a negative result. Growth was examined for colonial morphology including size, consistency, shape, hemolysis and ability to ferment lactose. For gram negative isolates, convectional biochemical test were performed [20]. 
A pure colony of the bacterial isolate was mixed with $0.85 \%$ normal saline and adjusts to obtain a 0.5 McFarland standard density required for antibiotic susceptibility testing. Bacterial isolates were tested against the following antibiotic panel commonly used - for gram negative bacteria:

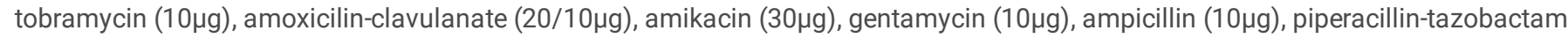
$(100 / 10 \mu \mathrm{g})$, cefotaxime $(30 \mu \mathrm{g})$, cefepime $(30 \mu \mathrm{g})$, ceftriaxone $(30 \mu \mathrm{g})$,ciprofloxacin $(5 \mu \mathrm{g})$, impenem/meropinem $(10 \mu \mathrm{g})$,trimethoprimsulfamethoxazole $(1.25 / 23.75 \mu \mathrm{g})$ were tested. The Kirby-Bauer disk diffusion method was used for susceptibility testing using Muller Hinton agar and the standard interpretative zone size criteria from the current CLSI standards [21].

\section{Detection of Carbapenem Resistance}

All carbapenem resistance or intermediate isolates were phenotypically confirmed for the presence of carbapenemase using the modified carbapenem inactivation test ( $\mathrm{mCIM}$ ) to identify carbapenem resistant Enterobacteriacae (CRE) isolates as recommended by CLSI [21].

\section{Detection of extended spectrum beta-lactamase}

Initial screening for ESBL used the diameters of zones of inhibition produced by ceftazidime $(30 \mu \mathrm{g})$, ceftriaxone $(30 \mu \mathrm{g})$ and cefotaxime $(30 \mu \mathrm{g})$ measured within the CLSI screening criteria. These breakpoints that indicate ESBL production are ceftazidime $\leq 22 \mathrm{~mm}$, ceftriaxone $\leq 25 \mathrm{~mm}$ and cefotaxime $\leq 27 \mathrm{~mm}$. Phenotypic detection of ESBL production was confirmed by conducting a double disk synergy test and combined disk test according to CLSI guideline [21].

\section{Combined disk (double disk potentiate) test (CDT)}

Ceftazidime $(30 \mu \mathrm{g})$ disk and cefotaxime $(30 \mu \mathrm{g})$ disks were used alone and in combination with clavulanic acid $(30 \mu \mathrm{g} / 10 \mu \mathrm{g})$ for phenotypic confirmation of the presence of ESBLs. A $\geq 5 \mathrm{~mm}$ increase in zone diameter for either of the cephalosporin disks and their respective cephalosporin/clavulanate disks were interpreted as an ESBL producer. According to CLSI, this method is used as a reference phenotypic method for comparing double disk synergy method [21].

\section{Double Disk Synergy test (DDST)}

The test isolate was spread onto a Mueller-Hinton agar plate. Ceftriaxone (30 $\mu \mathrm{g})$, cefotaxime $(30 \mu \mathrm{g})$, ceftazidime $(30 \mu \mathrm{g}), \mathrm{aztreonam}(30 \mu \mathrm{g})$ and amoxicillin/ clavulanic acid (20/10 $\mu \mathrm{g}$ disks were placed at distances of $20 \mathrm{~mm}$ (edge to edge) from the amoxicilin-clavulanate acid disk placed in the middle of the plate. After 24-h incubation, an enhanced zone of inhibition between either of the cephalosporin antibiotics and the Amoxicillin/Clavulanic acid disk is interpreted as a positive test [21].

\section{Data quality assurance}

Media was prepared as per manufacturer instructions and the laboratory Standard Operating Procedures (SOP) was strictly followed. Media were within expiration date and quality control parameters were used as defined in the CLSI standards.

Use ATCC control strain for each isolated bacterium included E. coli 25922, Pseudomonas aeruginosa 27853, and H. influenzae 10479, K.pnuemoniae 700603, S.typhimurium 13311. The results were reported on a log sheet and isolates were stored at $-80 \mathrm{c}$ in skim milk.

\section{Data analysis and interpretation}

Statistical package for social science (SPSS) versions 20.0 was employed to analyze the work and to make inferences on the frequency of occurrence of the bacterial pathogens associated with febrile illness and to show resistance patterns. Descriptive statistics to analysis used frequency, proportions graphs, and crosstabs and odds ratio. Bivariate analysis was performed for each factor associated with bloodstream infection. Regression analysis was conducted to identify associated factors and how they are associated with dependent variables .The strength of association was presented by odds ratio and $95 \%$ confidence interval and p-value of $<0.05$ was considered as statistical significant association.

\section{Results}

\section{Socio-demographic characteristics}

Among the study participants 122 (35.9\%) were males and 218 (64.1\%) were females resulting in an overall female to male ratio of $1.7: 1$. The mean age of pediatrics participated in this study was $1.04 \pm 1.0$ (SD) years. In regarding to patients location 76 (22.4\%) were from pediatric OPD and $181(53.2 \%), 83(24.4 \%)$ from inpatient ward and ICU ward respectively. The proportion of culture positive patients in the ICU $59 / 83$ (71.1\%), inpatient 66/181(36.5\%) and pediatric OPD 10/76 (13.2\%) patients were identified (Table 1). 


\section{Clinical features}

Patients showed different clinical diagnoses before confirmed their BSI in blood culture, most of were sepsis 102 (30.0\%) followed by early onset of neonatal sepsis /EoNS/ 71 (20.9\%), late onset neonatal sepsis/LoNS 48(14.1\%) and hospital acquired infection 43(12.6\%). However, the distribution of positive blood cultures among patients with different clinically diagnosed diseases suspected of having BSI showed that among clinical disease in endocarditis 7/11(63.6\%), hospital acquired infection 26/43(60.5\%), sepsis 49/102 (48\%) and late neonatal sepsis $21 / 48$ ( 44\%) high positive blood culture were identified as shown (Figure1).

\section{Bacteria pathogens among blood stream infection}

Of 340 paired blood sample bottles, a total of 137(40.2\%) bacterial pathogens were isolated from pediatric patients suspected of BSI with febrile illness. Among positive blood culture results about $54 \%$ were Gram negative bacteria with Klebsiella pneumoniae having the highest incidence of $31.4 \%$ followed by Acinitiobacter species (8.7\%). Double infection from Pseudomonas species and Klebsiella oxytoca were identified in one patient as shown (Figure2).

\section{Antimicrobial susceptibility testing}

Trends in prescribing antibiotics were assessed prior to blood sample collection before 7 days and 148 (43.5\%) participants received antibiotics empirically of which 49(33.1\%) were culture positive during. Ampicillin and gentamicin were among the most common empirically prescribed antibiotics. Culture isolation of 74 gram negative bacteria were tested with 12 antibiotics and demonstrated that the most prescribed antibiotics cotrimoxazole, gentamicin, and ciprofloxacin showed high resistance.

\section{Antimicrobial susceptibility pattern of Gram negative bacterial isolates}

A total of 74 gram negative isolates with exception of Salmonella species, were tested with beta-lactam antibiotics, fluoroquinolones, aminoglycosides, and carbapenems. The predominant gram negative isolate from BSI was Klebsiella pneumoniae which showed resistance to ampicillin (100\%) and cotrimosazole (90.7\%) but the isolates were susceptible to meropenem (62.8\%) and Piperacillin-Tazobactam (58.1\%). All Acinetobacter species were highly resistance to cefepime (100\%), ceftazidime (90.9\%), 72.7\% for meropenem and ciprofloxacin. Pseudomonas species also showed $50 \%$ resistance to anti-pseudomonal antibiotics gentamycin, ciprofloxacin, cefepime, amikacin and ceftazidime but was $75 \%$ susceptible to meropenem and piperacillin-tazobactam. Both Salmonella species were completely susceptible to ciprofloxacin, ceftriaxone and ampicillin but $50 \%$ of the isolates we resistant to cotrimoxazole [Table 2].

\section{Multi-drug resistant isolates}

Sixty two (83.7\%) of the isolates were shown to be resistant to three or more classes of the antibioties considered as multidrug resistance organisms. Pseudomonas aeruginosa showed that two (50\%) of the isolates exhibit resistance to three antibiotic classes. In Klebsiella pneumoniae, $38(88.4 \%)$ of the isolates were MDR. Among eleven Acinetobacter species $8(72.2 \%)$ of the isolates were resistance to more than three classes of antimicrobials. The least isolate of gram negative bacteria was Enterobacter cloacae 1 (100\%) exhibits high MDR which was resistance to eight or more antibiotics. However there was no MDR in Citrobacter and Salmonella species (Table 3).

\section{Carbapenem resistant Enterobacteriaceae (CRE)}

Out of 59 Enterobacteriaceae isolates, 18 (30.5\%) were resistant to carbapenems by producing carbapenemase as phenotypically confirmed by mCIM and 41 (69.5\%) were sensitive. The carbapenem resistance for Enterobacteriaceae species in our study was Klebsiella pneumoniae 27.1\% $(n=16 / 59)$ followed by Klebsiella oxytoca $3.4 \%(n=2 / 59)$. Moreover, other gram negative non- Enterobacteriaceae isolates capable of developing carbapenem resistance were identified in Acinetobacter species 12.2\% ( $n=9 / 74)$ and Pseudomonas aeruginosa $1.3 \%(n=1 / 74)$ of all gram negative isolates.

\section{Extended spectrum beta-lactamase producing Enterobacteriaceae}

Screening tests showed a total of 74 gram negative bacteria 59(79.7\%) Enterobacteriaceae isolates were suspected ESBL producing organisms. Klebsiella pneumoniae $27.1 \%(\mathrm{n}=16 / 59)$ and Escherichia coli $1.7 \%(\mathrm{n}=1 / 59)$ were among gram negative Enterobacteriaceae isolates identified as ESBL producers.

Combined disk (double disk potentiate) test (CDT): The overall prevalence of ESBL producing Enterobacteriaceae was $28.8 \%$ ( $\mathrm{n}=17 / 59)$. Among the suspected 17 isolates, $100 \%(n=17 / 17)$ were phenotypically confirmed as ESBL using combination disk method, with K. pneumoniae $100 \%$ $(n=16 / 16)$ and E. coli $100 \%(n=1 / 1)$ were positive. This result was used since the CLSI standard recommends this technique as a reference for other phenotypic methods. This test result was compared to the findings of the double disk method. 
Double Disk Synergy Test (DDST): All isolates $(n=17)$ were further tested for ESBL production using the double disk synergy procedure which is another phenotypic confirmatory method. The double disk synergy method indicated $82.3 \%$ ( $n=14 / 17)$ were confirmed as ESBL producing Enterobacteriaceae. Thus, K. pneumoniae demonstrated $100 \%(n=17 / 17)$ positive by the reference $(C D T)$ method, $82.3 \%(n=14 / 17)$ were positive by this method (DDST) while $17.6 \%(n=3 / 17)$ were negative. However $E$. coli $100 \%(n=1 / 1)$ was ESBL positive concordant done by two methods.

\section{Discussion}

Blood stream infection (BSI) in pediatric patients associated with febrile illness is a major public health problem especially in developing countries where there are high child morbidity and mortality rates. Accordingly, the timely detection of bacteremia in blood cultures is a promising diagnostic tool established to rule out bacteremia. The determination of the antimicrobial susceptibility profile is necessary for clinicians to determine appropriate empirical therapy, which ultimately decreases the emergence of drug resistance [22]. The present study included 340 pediatric patients under five years of age clinically diagnosed with different diseases suspected of causing bacteremia. Even though there was no statistically significant association for endocarditis $(63 \%)$, hospital acquired infection $(60 \%)$ and sepsis $(48 \%)$ patients accounted for the highest proportion of positive blood cultures [Table1].

In this study, overall prevalence of bloodstream infection based on significant bacterial growth in the blood cultures obtained from suspected patients was 137 (40.2\%). This was in agreement for other studies which demeonsrated a prevalence range of $35 \%-45 \%$ in line with the study done in Gondar, Ethiopia was 39.5\% [23] and other similar studies conducted in African countries such as in Egypt 40.7\% [24] and Tanzania $38.9 \%$ [25] as well as in India by Zakariya et al., $41.6 \%$ [26] and Khanal et al., [27] who reported $44 \%$ positive blood cultures. Meanwhile, the present study was higher than the studies conducted in Addis Ababa, Ethiopia 13.0\% [28], 27.9\% [23], and other African counties such as Tanzania 7.7\% [29] and Ghana 19.9\% [30]. The difference between these studies might be due to differences patient status in which our study included more patients from ICU and inpatients than outpatients. Furthermore blood cultures were performed by using the more sensitive automated BacT/ALERT system. However we have isolated bacteria lower than the studies in Nigeria 47.6\% [31], this was due to the patient status in which others only include inpatient and also isolated anaerobic bacteria.

Among the total isolates, $54 \%$ gram negative bacteria caused blood stream infections in children which is in keeping with the previous study done in Addis Ababa, Ethiopia 51.8\% [23], India 51.8\% [32], Kabul, Afghanistan 51.7\%[ 33], and Nepal 55.2\%, 56\% [34] respectively. However it was higher compared to the study done in USA by Larru., et al., 22\%[35] and in South Africa by Crichton et al., 40.7\% [36], this was due to difference in socioeconomic, geographical and infection control mechanisms.

In this study, the most common causes of bloodstream infections were gram-negative bacteria, in particular Klebsiella pneumoniae $31.4 \%$ followed by Acinitobacter species 8.7\%. This was supported by the study done in Jimma Ethiopia 31.4\% [37], Kenya 13\%[38], Ghana 26\% [39], Bouaké, central Côte d'Ivoire 22.5\%[40] in Asian such as in India by 25.8\%,30.5\%[41,42] in Brazil, Latin America [43], Vietnam 20\% [44] where the most common isolate was Klebsiella pneumoniae. However the predominant GNB isolation rate varied from country to country where in India by Kante et al., [45], Indonesia by Murni et al., [46] frequently isolated pathogen in BSI was Pseudomonas other than Klebsiella pneumoniae in the same age group. This might be explained by different practices in prescribing antibiotics for empirical treatment prior to blood culture collection and differences in the management of nosocomial infections across counties. Furthermore, in our hospital setting, nosocomial infections did not receive the necessary infection control and preventative measures. Which further increase the survival of highly drug resistant bacteria including Klebsiella pneumoniae.

A polymicrobial infection in our study was found in a single patient and both gram negative isolates tended to increase the severity of the diseases. This is in agreement with a previous study even though some microbiologists consider polymicrobial growth as contamination, but nonetheless sepsis should be clinically correlated [47].

The trend of empirical treatment in our study $43.5 \%$ and the most prescribed antibiotics were ampicillin, gentamicin, ciprofloxacin and third generation cephalosporin (most common ceftriaxone) in which ampicillin and gentamicin were the most common combined drugs used. This was supported by the previous study in, Ghana [48].

The antimicrobial susceptibility of Klebsiella pneumoniae isolates gave high levels of resistance to ampicillin(100\%), cotrimoxazole (90.7\%) and gentamycin (88.4\%), despite of sensitive to meropenem (62.8\%), Piperacillin-Tazobactam (58.1\%) which was consistent with the studies by Zenebe et al [49] 100\%resistance to ampicillin and Cotrimosazole, in Bahirdar ,Ethiopia by Hailu et al.,[50] ampicillin 91.4\%,cotrimosazole 77.1\% and gentamicin $71 \%$ while in India the resistance of ampicillin, cotrimosazole and gentamycin done by Kumar et al.,[41] were $97 \%, 88 \%, 67 \%$ respectively. it was also comparable in Kaneti children Hospital, Nepal by kari et al [51] reported 100\% resistance to ampicillin and least sensitive to Cotrimosazole and Gentamycin. The more potent drugs of the $3^{\text {rd }}$ and $4^{\text {th }}$ generation cephalosporin, quinolones and carbapenem antibiotics also showed resistance which is a concern for treatment of BSI in pediatrics with septicemia. 
The second most predominant isolates in our study were Acinetobacter species which demonstrated resistance to most antimicrobials tested: ceftazidime $100 \%$, cefepime $90.9 \%$, gentamycin $81.8 \%$, tobramycin $81.8 \%$, ciprofloxacin $72.7 \%$, meropenem $72.7 \%$ which was comparable with other previous studies $[52,53]$. However our result gave a higher rate of resistance compared to a study conducted in South India, [54] in which isolates were meropenem $100 \%$ sensitive, while $67 \%$ were sensitive to gentamicin, ceftriaxone, ciprofloxacin, ceftazidime and Amikacin. This is due to our greater number of isolates and might be due to the inappropriate empirical use of meropenem as the first line treatment since most of isolates are from ICU patients in our hospital.

The overall prevalence of multidrug resistance isolates in our study was $83.7 \%$ Gram-negative bacteria with a high resistance to beta-lactam antibiotics. This result is supported by a previous study in Ethiopia [19]. Among Klebsiella species 87.7\%(43/49) and Acinetobacter 72.2\% were the predominant MDR species which was consistent with the study in north India [55].

The present study identified carbapenem resistant Enterobacteriaceae (CRE) with a rate of 30.5\% comparable with a study conducted in Tanzania 35\% [56]. Most carbapenem resistance was detected in 72.2\% of Acinetobacter isolates and $62.8 \%$ of Klebsiella pneumoniae.

The prevalence of ESBL-producing Enterobacteriaceae in our study is 25.4\%. Among 43 Klebsiella pneumoniae isolates $14(32.5 \%)$ and 5 E.coli isolates 1(20.0\%) are ESBL-producers. This is in keeping with the study conducted in south India by Zakariya et al., 32.0\% [54] and in Mali by Sangare et al., 29.4\% [57] for ESBL producing Klebsiella pneumoniae.

\section{Limitations}

Even though our study identifies numerous bacteria pathogens causing BSI in pediatrics under five years, we could not able to isolate other possible pathogens including anaerobic bacteria. Due to supply shortage molecular characterization was not performed.

\section{Conclusions}

Blood stream infection in pediatric patients caused by Gram negative organisms with high antibiotic resistance were a treat of children. Among the dominate gram negative isolates Klebsiella pneumoniae and Acinitobacter species were multidrug resistant to 3rd and 4th generation cephalosporin, quinolones, aminoglycosides, and carbapenem. The prevalence rates of MDR $83.7 \%$, CRE $30.5 \%$ and ESBL $25.4 \%$ are high in gram negative bacterial isolates. in this study and are of major concern: duration of hospitalization, a history of hospital acquired infections and complications of clinically suspected septicemia with high grade fever were statistically significant and associated with positive blood culture in pediatric patients $(\mathrm{p}<0.05)$.

Based on our findings, we recommend that blood culture should be taken for pediatric patients prior to antimicrobial therapy with most sensitive BacT/Alert machine. Clinicians should avoid prescribing last line antibiotics first for pediatrics in ICU.

Since the majority of antibiotics even last line antibiotics alarmingly resistance, laboratory based testing should be routinely conducted so as to provide the clinician definitive laboratory data and therefore enable improved patient management.Confirmed nosocomial infection requires patient isolation and is mandatory to minimize transmission of resistance genes including CRE, MDR and ESBL producing organisms in hospitalized patients.

Strengthening of antimicrobial surveillance system and antimicrobial stewardship programs are necessary for better management of antibiotics selection in addition to infection prevention practices in hospital settings.

\section{Abbreviations}

ATCC- American type of culture collection, BSI-blood stream infection, CLSI-clinical laboratory standard institute, CRE-carbapenem resistance Enterobacteriaceae, ESBL-extended spectrum beta lactamase, GNB - gram negative bacteria, ICU-intensive care unit, MDR - Multi drug resistance.

\section{Declarations}

The author's declare that the study is their original work

\section{Ethics approval and consent to participate}

The study was conducted after it was approved by the department of Medical Laboratory Sciences research and ethics review committee (DRERC), school of Allied health sciences, College of Health Sciences, Addis Ababa University (Ref.No: 132645/18) . An informed consent was obtained from mother /guardian before collection of blood specimens and results were used in the management of patients. Written consent was sought for the study and any information related with the patient result and clinical history was kept confidential. 
Consent for Publication

Not applicable

Availability of data and material

The data is available in first author and can provide when necessary

\section{Competing interests}

We declare the is no competing interest

Funding

Not available

\section{Authors' contributions}

$\mathrm{MM}$, topic selection, designed the study protocol, participated in data collection, performed analysis, interpretation and wrote the research thesis, ZA, wrote the first and final draft of the manuscript for publication, KD, advised and approved the research topic selection, provide the inputs during analysis and interpretation of the whole research paper. All authors read and approved the final manuscript.

\section{Acknowledgements}

We express our grateful appreciation to Martin R Evans, PhD, CLT, MT (ASCP), Laboratory Director Hub SME, Ethiopia AMR Laboratory ECHO Pilot, American Society for Microbiology Consultant, New York for assistance in English grammer editing service and moderated this paper and improved the manuscript significantly.

\section{Authors' Information}

${ }^{1}$ Department of Microbiology Laboratory, Tikur Anbessa Specialized Hospital, Addis Ababa University, Ethiopia. ${ }^{2}$ Ethiopian public health institutes, Addis Ababa, Ethiopia. ${ }^{3}$ Departments of Microbiology and Parasitology, Addis Ababa University, Ethiopia.

\section{References}

1. Saeed M, Rasheed F, Ashraf F, Iram S, Hussain S, Khawaja AR. PATHOGENS CAUSING BLOOD STREAM INFECTIONS. The Professional Medical Journal. 2015; 22(12):1617-23.

2. Diekma DJ, Beekman SE, Chapin KC, Morel KA, Munson E, Deorn GV: Epidemiology and outcome of nosocomial and community onset bloodstream infection. J ClinMicrobio/ 2003, 41:3655-3660.

3. Aiken AM, Mturi N, Njuguna P, Mohammed S, Berkley JA, Mwangi I, Mwarumba S, Kitsao BS, Lowe BS, Morpeth SC, Hall AJ. Risk and causes of paediatric hospital-acquired bacteraemia in Kilifi District Hospital, Kenya: a prospective cohort study. The Lancet. 2011; 378(9808):20217.

4. Karunakaran R, Raja NS, Ng KP, Navaratnam P. Etiology of blood culture isolates among patients in a multidisciplinary teaching hospital in Kuala Lumpur. JOURNAL OF MICROBIOLOGY IMMUNOLOGY AND INFECTION. 2007; 40(5):432-7.

5. Becker JU, Theodosis C, Jacob ST, Wira CR, Groce NE: Surviving sepsis in low-income and middle-income countries: new directions for care and esearch. Lancet Infect Dis. 2009, 9(Suppl 9):577-582.

6. Tziamabos AO, Kasper DL. Principle and practice of infectious diseases. Frank Polizano J. 2005; 26:2810-6.

7. Madsen KH, Sorensen HT: Secular trends in incidence and mortality of bacteremia in Danish country. APMIS1999, 107:346-352.

8. Zenebe T, Kannan S, Yilma D, Beyene G. Invasive bacterial pathogens and their antibiotic susceptibility patterns in Jimma University specialized Hospital, Jimma, and Southwest Ethiopia. Ethiopian journal of health sciences. 2011; 21(1):1-8.

9. Harbarth S, Ferrière K, Hugonnet S, Ricou B, Suter P, Pittet D: Epidemiology and prognostic determinants of bloodstream infections in surgical intensive care. Arch Surg. 2002, 137:1353-1359.

10. Ibrahim EH, Sherman G, Ward S: The influence of inadequate antimicrobial treatment of bloodstream infections on patient outcomes in the ICU setting. 2000, 118:146-155.

11. World Health Organization. Antimicrobial resistance: global report on surveillance. Geneva: World Health Organization. 2014.

12. Leistner R, Gürntke S, Sakellariou C, Denkel LA, Bloch A, Gastmeier P, Schwab F. Bloodstream infection due to extended-spectrum betalactamase (ESBL)-positive K. pneumoniae and E. coli: an analysis of the disease burden in a large cohort. Infection. 2014; 42(6):991-7.

13. Leistner R, Sakellariou C, Gurntke S, Kola A, Steinmetz I, Kohler C, et al. Mortality and molecular epidemiology associated with extendedspectrum beta-lactamase production in Escherichia coli from bloodstream infection. Infect Drug Resist. $2014 ;$ 7:57-62. 
14. Willmann M, Kuebart I, Marschal M, Schroppel K, Vogel W, Flesch I, et al. Effect of metallo-beta-lactamase production and multidrug resistance on clinical outcomes in patients with Pseudomonas aeruginosa bloodstream infection: a retrospective cohort study. BMC Infect Dis. 2013; $13: 515$.

15. Vlieghe E, Phoba MF, Tamfun JJM, Jacobs J. Antibiotic resistance among bacterial pathogens in Central Africa: a review of the published literature between 1955 and 2008. Int J Antimicrob Agents. 2009; 34(4):295-303.

16. Ashley EA, Lubell Y, White NJ, Turner P. Antimicrobial susceptibility of bacterial isolates from community acquired infections in Sub-Saharan Africa and Asian low and middle income countries. Trop Med Int Health. 2011; 16(9):1167-1179.

17. Moss W. An outbreak of gentamicin-resistant Klebsiella bacteraemia at a children's hospital. Ethiopian medical journal. 1992; 30(4):197-205.

18. http://www.aau.edu.et/services/Hospital/background-of-college-of-health-sciences/

19. Negussie A, Mulugeta G, Bedru A, Ali I, Shimeles D, Lema T, Aseffa A. Bacteriological profile and antimicrobial susceptibility pattern of blood culture isolates among septicemia suspected children in selected hospitals Addis Ababa, Ethiopia. International journal of biological and medical research. 2015; 6(1):4709.

20. Thorpe TC, Wilson ML, Turner JE, DiGuiseppi JL, Willert M, Mirrett S, Reller LB. BacT/Alert: an automated colorimetric microbial detection system. Journal of clinical microbiology. 1990; 28(7):1608-12.

21. Wayne PA. Clinical and laboratories standards institute. Performance standards for antimicrobial susceptibility testing; 27 th informational supplement. Clinical and laboratories standards institute CLSI document M100. 2017.

22. Slonim AD, Kurtines HC, Sprague BM, Singh N. The costs associated with nosocomial bloodstream infections in the pediatric intensive care unit. Pediatric Critical Care Medicine. 2001;2(2):170-4.

23. Abebaw A, Tesera H, Belachew T, Mihiretie GD. The bacterial profile and antibiotic susceptibility pattern among patients with suspected bloodstream infections, Gondar, north-west Ethiopia. Pathology and Laboratory Medicine International. 2018; 10:1-7.

24. El-Din S, Rabie EM, El-Sokkary MM, Bassiouny MR, Hassan R. Epidemiology of neonatal sepsis and implicated pathogens: a study from Egypt. BioMed research international. 2015; 1-11

25. Kayange N, Kamugisha E, Mwizamholya DL, Jeremiah S, Mshana SE. Predictors of positive blood culture and deaths among neonates with suspected neonatal sepsis in a tertiary Hospital, Mwanza-Tanzania. BMC pediatrics. 2010; 10(1):39.

26. Zakariya BP, Bhat V, Harish BN, Babu TA, Joseph NM. Neonatal sepsis in a tertiary care Hospital in South India: bacteriological profile and antibiotic sensitivity pattern. The Indian Journal of Pediatrics. 2011; 78(4):413-7.

27. Khanal B, Harish BN, Sethuraman KR, Srinivasan S. Infective endocarditis: report of a prospective study in an Indian Hospital. Tropical doctor. $2002 ; 32(2): 83-5$.

28. Seboxa T, Amogne W, Abebe W, Tsegaye T, Azazh A, HailuW,et al. High mortality from blood stream infection in Addis Ababa, Ethiopia, is due to antimicrobial resistance. PloS one. 2015; 10(12):e0144944.

29. Mahende C, Ngasala B, Lusingu J, Butichi A, Lushino P, LemngeM,et al. Bloodstream bacterial infection among outpatient children with acute febrile illness in north-eastern Tanzania. BMC research notes. 2015;8(1):1178-9.

30. Nielsen MV, Sarpong N, Krumkamp R, Dekker D, Loag W, Amemasor S, et al. Incidence and characteristics of bacteremia among children in rural Ghana. PloS one. 2012; 7(9):e44063.

31. Meremikwu MM, Nwachukwu CE, Asuquo AE, Okebe JU, Utsalo SJ. Bacterial isolates from blood cultures of children with suspected septicaemia in Calabar, Nigeria. BMC infectious diseases. 2005; 5(1):110.

32. Singh AK, Venkatesh V, Singh RP, Singh M. Bacterial and antimicrobial resistance profile of bloodstream infections: a Hospital-based study. CHRISMED Journal of Health and Research. 2014; 1(3):140.

33. Tariq TM. Bacteriologic profile and antibiogram of blood culture isolates from a children's hospital in Kabul. J Coll Physicians Surg Pak. $2014 ; 24(6): 396-9$.

34. Shrestha S, Amatya R, Shrestha RK, Shrestha R. Frequency of Blood Culture Isolates and their Antibiogram in a Teaching Hospital. J Nepal Med Assoc .2014; 52(193):692-7

35. Larru B, Gong W, Vendetti N, Sullivan KV, Localio R, Zaoutis TE, et al. Bloodstream infections in Hospitalized children: epidemiology and antimicrobial susceptibilities. The Pediatric infectious disease journal. 2016; 35(5):507-10.

36. Crichton H, O'Connell N, Rabie H, Whitelaw AC, Dramowski A. Neonatal and paediatric bloodstream infections: Pathogens, antimicrobial resistance patterns and prescribing practice at Khayelitsha District Hospital, Cape Town, South Africa. SAMJ: South African Medical Journal. 2018; 108(2):99-104.

37. Abrha A, Abdissa A, Beyene G, Getahun G, Girma T. Bacteraemia among severely malnourished children in Jimma university hospital, Ethiopia. Ethiopian journal of health sciences. 2011;21(3):175-182.

38. Talbert AW, Mwaniki M, Mwarumba S, Newton CR, Berkley JA. Invasive bacterial infections in neonates and young infants born outside Hospital admitted to a rural Hospital in Kenya. Pediatr Infect Dis J. 2010; 29(10):945-9.

Page $9 / 14$ 
39. Nielsen MV, Sarpong N, Krumkamp R, Dekker D, Loag W, Amemasor S, et al. Incidence and characteristics of bacteremia among children in rural Ghana. PLoS One. 2012; 7(9):e44063.

40. Akoua-Koffi C, Tia H, Plo JK, Monemo P, Cissé A, Yao C, et al. Epidemiology of community-onset bloodstream infections in Bouaké, central Côte d'Ivoire. New microbes and new infections. 2015; 7:100-4.

41. Kumar S, Rizvi M, Vidhani S, Sharma VK. Changing face of septicaemia and increasing drug resistance in blood isolates. Indian journal of pathology \& microbiology. 2004; 47(3):441-6.

42. Jyothi P, Basavaraj MC, Basavaraj PV. Bacteriological profile of neonatal septicemia and antibiotic susceptibility pattern of the isolates. Journal of natural science, biology, and medicine. 2013; 4(2):306-9.

43. Berezin EN, Solórzano F. Gram-negative infections in pediatric and neonatal intensive care units of Latin America. The Journal of Infection in Developing Countries. 2014; 8(08):942-53.

44. Kruse AY, ThieuChuong DH, Phuong CN, Duc T, Graff Stensballe L, Prag J, et al. Neonatal bloodstream infections in a pediatric Hospital in Vietnam: a cohort study. Journal of tropical pediatrics. 2013; 59 (6):483-8.

45. Kante M, Lakshmi PM, Sreenivasulu Reddy PS. Bacterial profile of blood stream infections and their antibiograms. Int J Res Med Sci. 2015; 3(3):698-704.

46. Murni IK, Duke T, Kinney S. Antibiotic resistance and mortality in children with nosocomial bloodstream infection in a teaching hospital in Indonesia. Southeast Asian J Trop Med Public Health. 2016; 47:983-3.

47. Dagnew M,Yismaw G, Gizachew M, Gadisa A, TigistAbebe T, Tadesse T et al. Bacterial profile and antimicrobial susceptibility pattern in septicemia suspected patients attending Gondar University Hospital, Northwest Ethiopia. BMC Res Notes. $2013 ; 6$ : 283.

48. Acquah SE, QuayeL,Sagoe K, Ziem JB, Bromberger PI and Amponsem AA. Susceptibility of bacterial etiological agents to commonly-used antimicrobial agents in children with sepsis at the Tamale Teaching Hospital. BMC Infectious Diseases .2013; 13:89.

49. Zenebe T, Kannan S, Yilma D, Beyene G. Invasive bacterial pathogens and their antibiotic susceptibility patterns in Jimma University specialized Hospital, Jimma, and Southwest Ethiopia. Ethiopian journal of health sciences. 2011; 21(1):1-8.

50. Hailu D, Abera B, Yitayew G, Mekonnen D, Derbie A. Bacterial blood stream infections and antibiogram among febrile patients at Bahir Dar Regional Health Research Laboratory Center, Ethiopia. Ethiopian Journal of Science and Technology. 2016; 9(2):103-12.

51. Karki S, Rai GK, Manandhar R. Bacteriological analysis and antibiotic sensitivity pattern of blood culture isolates in Kanti children Hospital. Journal of Nepal Pediatric Society. 2010; 30(2):94-7.

52. Shrestha S, Amatya R, Shrestha RK, Shrestha R. Frequency of blood culture isolates and their antibiogram in a teaching Hospital. Journal of Nepal Medical Association. 2014; 52(193):692-7.

53. Pereira CA, Marra AR, Camargo LF, Pignatari AC, Sukiennik T, Behar PR., et al. Nosocomial bloodstream infections in Brazilian pediatric patients: microbiology, epidemiology, and clinical features. PloS one. 2013; 8(7):e68144.

54. Zakariya BP, Bhat V, Harish BN, Babu TA, Joseph NM. Neonatal sepsis in a tertiary care Hospital in South India: bacteriological profile and antibiotic sensitivity pattern. The Indian Journal of Pediatrics. 2011; 78(4):413-7.

55. Gill MK, Sharma S. Bacteriological profile and antibiotic resistance pattern in blood stream infection in critical care units of a tertiary care Hospital in North India. Indian Journal of Microbiology Research. 2016; 3(3):270-4.

56. Mushi MF, Mshana SE, Imirzalioglu C, Bwanga F. Carbapenemase genes among multidrug resistant gram negative clinical isolates from a tertiary Hospital in Mwanza, Tanzania. BioMed research international. 2014; 1-6.

57. Sangare SA, Maiga Al, Guindo I, Maiga A, Camara N, Dicko OA., et al. Prevalence of ESBL-producing Enterobacteriaceae isolated from blood cultures in Mali. The Journal of Infection in Developing Countries. 2016; 10(10):1059-64.

\section{Tables}

Table 1: Distribution of socio-demographic and clinical condition of pediatric patients suspected of blood stream infection in Tikur Anbesa Specialized Hospital, 2018 


\begin{tabular}{|c|c|}
\hline Variables & Frequency (\%) \\
\hline \multicolumn{2}{|l|}{ Sex } \\
\hline Male & $122(35.9)$ \\
\hline Female & $218(64.1)$ \\
\hline \multicolumn{2}{|l|}{ Age group } \\
\hline Neonates (<28days) & $111(32.6)$ \\
\hline Infants (<1years) & $115(33.8)$ \\
\hline Children(<5years) & $114(33.5)$ \\
\hline \multicolumn{2}{|l|}{ Clinical condition } \\
\hline $\mathrm{CHF}$ & $29(8.5)$ \\
\hline Hospital acquired infection & $43(12.6)$ \\
\hline Early onset of neonatal sepsis & $71(20.8)$ \\
\hline Late onset of neonatal sepsis & $48(14.1)$ \\
\hline Sepsis & $102(30.0)$ \\
\hline Mengitidis & $3(0.8)$ \\
\hline Neuroblastoma & $5(1.5)$ \\
\hline Community acquired pneumonia & $7(2.0)$ \\
\hline Endocarditis & $11(3.2)$ \\
\hline Neutrophenic fever & $9(2.6)$ \\
\hline Othrs & $12(3.5)$ \\
\hline \multicolumn{2}{|l|}{ Unit of diagnosis } \\
\hline ICU & $83(24.4)$ \\
\hline Impatient & $181(53.2)$ \\
\hline Pediatric OPD & $76(22.4)$ \\
\hline \multicolumn{2}{|l|}{ Duration of admission } \\
\hline 1-2 days & 61(17.9) \\
\hline 3-4 days & $76(22.4)$ \\
\hline 5-6 days & $41(12.0)$ \\
\hline$\geq 7$ days & $84(24.7$ \\
\hline \multicolumn{2}{|l|}{ Cause of high fever } \\
\hline Suspected bacteremia & $340(100)$ \\
\hline Malaria & $0(0)$ \\
\hline Others (viral, fungal...) & $0(0)$ \\
\hline \multicolumn{2}{|l|}{ Symptom of BSI } \\
\hline High grade Fever only & $267(78.5)$ \\
\hline Mild Fever and others & $73(21.5)$ \\
\hline \multicolumn{2}{|l|}{ Antibiotics taken before 07 days } \\
\hline Yes & $148(43.5)$ \\
\hline No & $192(56.5)$ \\
\hline \multicolumn{2}{|l|}{ History Hospital acquired infection } \\
\hline yes & $42(12.4)$ \\
\hline No & $298(87.6)$ \\
\hline \multicolumn{2}{|l|}{ Complication of BSI } \\
\hline Yes & $92(27.0)$ \\
\hline No & $248(73.0)$ \\
\hline
\end{tabular}




\begin{tabular}{|c|c|c|c|c|c|c|c|c|c|c|c|c|c|}
\hline \multirow{2}{*}{$\begin{array}{l}\text { Gram } \\
\text { negative } \\
\text { Bacteria } \\
\text { isolates }\end{array}$} & & \multicolumn{12}{|c|}{ Antimicrobial susceptibility pattern } \\
\hline & & SXT & GEN & CIP & CRO & AMP & MEM & FEP & AMK & TORB & PZT & AGU & CAZ \\
\hline E.coli $(n=5)$ & $\begin{array}{l}\mathrm{R} \% \\
\mathrm{~S} \%\end{array}$ & $\begin{array}{l}5(100) \\
0(0)\end{array}$ & $\begin{array}{l}3(60.0) \\
2(40.0)\end{array}$ & $\begin{array}{l}5(100) \\
0(0)\end{array}$ & $\begin{array}{l}4(80.0) \\
1(20.0)\end{array}$ & $\begin{array}{l}4(80.0) \\
1(20.0)\end{array}$ & $\begin{array}{l}0(0) \\
5(100)\end{array}$ & $\begin{array}{l}4(80.0) \\
1(20.0)\end{array}$ & $\begin{array}{l}0(0) \\
5(100)\end{array}$ & $\begin{array}{l}4(80.0) \\
1(20.0)\end{array}$ & $\begin{array}{l}3(60.0) \\
2(40.0)\end{array}$ & $\begin{array}{l}3(60.0) \\
2(40.0)\end{array}$ & $\begin{array}{l}5(100) \\
0(0)\end{array}$ \\
\hline $\begin{array}{l}\text { P.aeruginosa } \\
(n=4)\end{array}$ & $\begin{array}{l}\mathrm{R} \% \\
\mathrm{~S} \%\end{array}$ & NA & $\begin{array}{l}2(50.0) \\
2(50.0)\end{array}$ & $\begin{array}{l}2(50.0) \\
2(50.0)\end{array}$ & NA & NA & $\begin{array}{l}1(25.0) \\
3(75.0)\end{array}$ & $\begin{array}{l}2(50.0) \\
2(50.0)\end{array}$ & $\begin{array}{l}2(50.0) \\
2(50.0)\end{array}$ & \begin{tabular}{|l|}
$1(25.0)$ \\
$3(75.0)$
\end{tabular} & $\begin{array}{l}1(25.0) \\
3(75.0)\end{array}$ & NA & $\begin{array}{l}2(50.0) \\
2(50.0)\end{array}$ \\
\hline $\begin{array}{l}\text { Klebsiella } \\
\text { pneumoniae. } \\
(n=43)\end{array}$ & $\begin{array}{l}\mathrm{R} \% \\
\mathrm{~S} \%\end{array}$ & $\begin{array}{l}39(90.7) \\
4(9.3)\end{array}$ & $\begin{array}{l}38(88.4) \\
5(11.6)\end{array}$ & $\begin{array}{l}38(88.4) \\
5(11.6)\end{array}$ & $\begin{array}{l}37(86.0) \\
6(14.0)\end{array}$ & $\begin{array}{l}43(100) \\
0(0)\end{array}$ & $\begin{array}{l}16(37.2) \\
27(62.8)\end{array}$ & $\begin{array}{l}38(88.4) \\
5(11.6)\end{array}$ & $\begin{array}{l}22(51.2) \\
20(46.5)\end{array}$ & $\begin{array}{l}38(88.4) \\
5(11.6)\end{array}$ & $\begin{array}{l}18(41.9) \\
25(58.1)\end{array}$ & $\begin{array}{l}37(86.0) \\
6(14.0)\end{array}$ & $\begin{array}{l}37(86.0) \\
6(14.0)\end{array}$ \\
\hline $\begin{array}{l}\text { Klebsiella } \\
\text { oxatica }(n=6)\end{array}$ & $\begin{array}{l}\mathrm{R} \% \\
\mathrm{~S} \%\end{array}$ & $\begin{array}{l}5(83.3) \\
1(16.7)\end{array}$ & $\begin{array}{l}3(50.0) \\
3(50.0)\end{array}$ & $\begin{array}{l}4(66.7) \\
2(33.3)\end{array}$ & $\begin{array}{l}6(100) \\
0(0)\end{array}$ & $\begin{array}{l}6(100) \\
0(0)\end{array}$ & $\begin{array}{l}2(33.3) \\
4(66.7)\end{array}$ & $\begin{array}{l}6(100) \\
0(0)\end{array}$ & $\begin{array}{l}3(50.0) \\
3(50.0)\end{array}$ & \begin{tabular}{|l}
$4(66.7)$ \\
$2(33.3)$
\end{tabular} & $\begin{array}{l}3(50.0) \\
3(50.0)\end{array}$ & $\begin{array}{l}6(100) \\
0(0)\end{array}$ & $\begin{array}{l}6(100) \\
0(0)\end{array}$ \\
\hline $\begin{array}{l}\text { Acinitobactor } \\
(n=11)\end{array}$ & $\begin{array}{l}\mathrm{R} \% \\
\mathrm{~S} \%\end{array}$ & NA & $\begin{array}{l}9(81.8) \\
2(18.2)\end{array}$ & $\begin{array}{l}11(72.7) \\
3(27.3)\end{array}$ & NA & NA & $\begin{array}{l}8(72.7) \\
3(27.3)\end{array}$ & $\begin{array}{l}10(90.9) \\
1(9.1)\end{array}$ & $\begin{array}{l}6(54.5) \\
5(45.5)\end{array}$ & \begin{tabular}{|l}
$9(81.8)$ \\
$2(18.2)$
\end{tabular} & $\begin{array}{l}6(54.5) \\
5(45.5)\end{array}$ & NA & $\begin{array}{l}11(100) \\
0(0)\end{array}$ \\
\hline $\begin{array}{l}\text { Entrobacter } \\
\text { clocae }(n=1)\end{array}$ & $\begin{array}{l}\mathrm{R} \% \\
\mathrm{~S} \%\end{array}$ & $\begin{array}{l}1(100) \\
0(0)\end{array}$ & $\begin{array}{l}1(100) \\
0(0)\end{array}$ & $\begin{array}{l}1(100) \\
0(0)\end{array}$ & $\begin{array}{l}1(100) \\
0(0)\end{array}$ & $\begin{array}{l}1(100) \\
0(0)\end{array}$ & $\begin{array}{l}0(0) \\
1(100)\end{array}$ & $\begin{array}{l}1(100) \\
0(0)\end{array}$ & $\begin{array}{l}0(0) \\
1(100)\end{array}$ & $\begin{array}{l}1(100) \\
0(0)\end{array}$ & $\begin{array}{l}1(100) \\
0(0)\end{array}$ & $\begin{array}{l}1(100) \\
0(0)\end{array}$ & $\begin{array}{l}1(100) \\
0(0)\end{array}$ \\
\hline $\begin{array}{l}\text { Citrobacter } \\
(n=1)\end{array}$ & $\begin{array}{l}\mathrm{R} \% \\
\mathrm{~S} \%\end{array}$ & $\begin{array}{l}1(100) \\
0(0)\end{array}$ & $\begin{array}{l}0(0) \\
1(100)\end{array}$ & $\begin{array}{l}0(0) \\
1(100)\end{array}$ & $\begin{array}{l}0(0) \\
1(100)\end{array}$ & $\begin{array}{l}1(100) \\
0(0)\end{array}$ & $\begin{array}{l}0(0) \\
1(100)\end{array}$ & $\begin{array}{l}0(0) \\
1(100)\end{array}$ & $\begin{array}{l}0(0) \\
1(100)\end{array}$ & \begin{tabular}{|l|}
$0(0)$ \\
$1(100)$
\end{tabular} & $\begin{array}{l}0(0) \\
1(100)\end{array}$ & $\begin{array}{l}1(100) \\
0(0)\end{array}$ & $\begin{array}{l}0(0) \\
1(100)\end{array}$ \\
\hline $\begin{array}{l}\text { Salmonella } \\
\operatorname{spp}(n=2)\end{array}$ & $\begin{array}{l}\mathrm{R} \% \\
\mathrm{~S} \%\end{array}$ & $\begin{array}{l}1(50.0) \\
1(50.0)\end{array}$ & NA & $\begin{array}{l}0(0) \\
2(100)\end{array}$ & $\begin{array}{l}0(0) \\
2(100)\end{array}$ & $\begin{array}{l}0(0) \\
2(100)\end{array}$ & NA & NA & NA & NA & NA & NA & NA \\
\hline
\end{tabular}

Table 2: Antimicrobial susceptibility of gram negative bacterial isolates associated with blood stream infection among pediatric patients in Tikur Anbesa Specialized Hospital, 2018

SXT-Sulphamethoxazol-trimethoperem/cotrimosazole, GN-Gentamycin, CIP-Ciprofloxacillin, CRO-ceftriaxone, AMP-ampicillin, MEM-Meropenem, FEPCefepime, AMK -Amikacin, CAZ- ceftazidime, Torbomycin, Piperacillin-Tazobactam, AGU_Augmentin/Amoxycillin-Clavulanic acid, NA- Not applicable

Table 3: prevalence of multi drug resistance among gram negative isolates from BSI in pediatric patients at Tikur Anbesa Specialized Hospital, 2018

\begin{tabular}{llll}
\hline & \multicolumn{3}{l}{ Prevalence } \\
\cline { 2 - 4 } Bacterial isolates & MDR (\%) & ESBL (\%) & CRE (\%) \\
E.coli $(n=5)$ & $4(80)$ & $1(20)$ & $0(00)$ \\
Pseudomonas $(\boldsymbol{n}=4)$ & $2(50)$ & $0(00)$ & $1(25)$ \\
Klebsiella pneumoniae. $(\boldsymbol{n}=43)$ & $38(88.4)$ & $14(32.5)$ & $16(37.2)$ \\
Klebsiella oxytoca $(\boldsymbol{n}=6)$ & $5(83.3)$ & $0(00)$ & $2(33.3)$ \\
Acinitobacter $(\boldsymbol{n}=11)$ & $8(72.7)$ & $0(00)$ & $8(72.7)$ \\
Entrobacter clocae $(\boldsymbol{n}=1)$ & $1(100)$ & $0(00)$ & $0(00)$ \\
Citrobacter $(\boldsymbol{n}=1)$ & $0(00)$ & $0(00)$ & $0(00)$ \\
Salmonella spp $(\boldsymbol{n}=3)$ & $0(00)$ & $0(00)$ & $0(00)$ \\
Total $(\boldsymbol{N}=74)$ & $62(83.7)$ & $15(20.2)$ & $26(35.1)$ \\
\hline
\end{tabular}




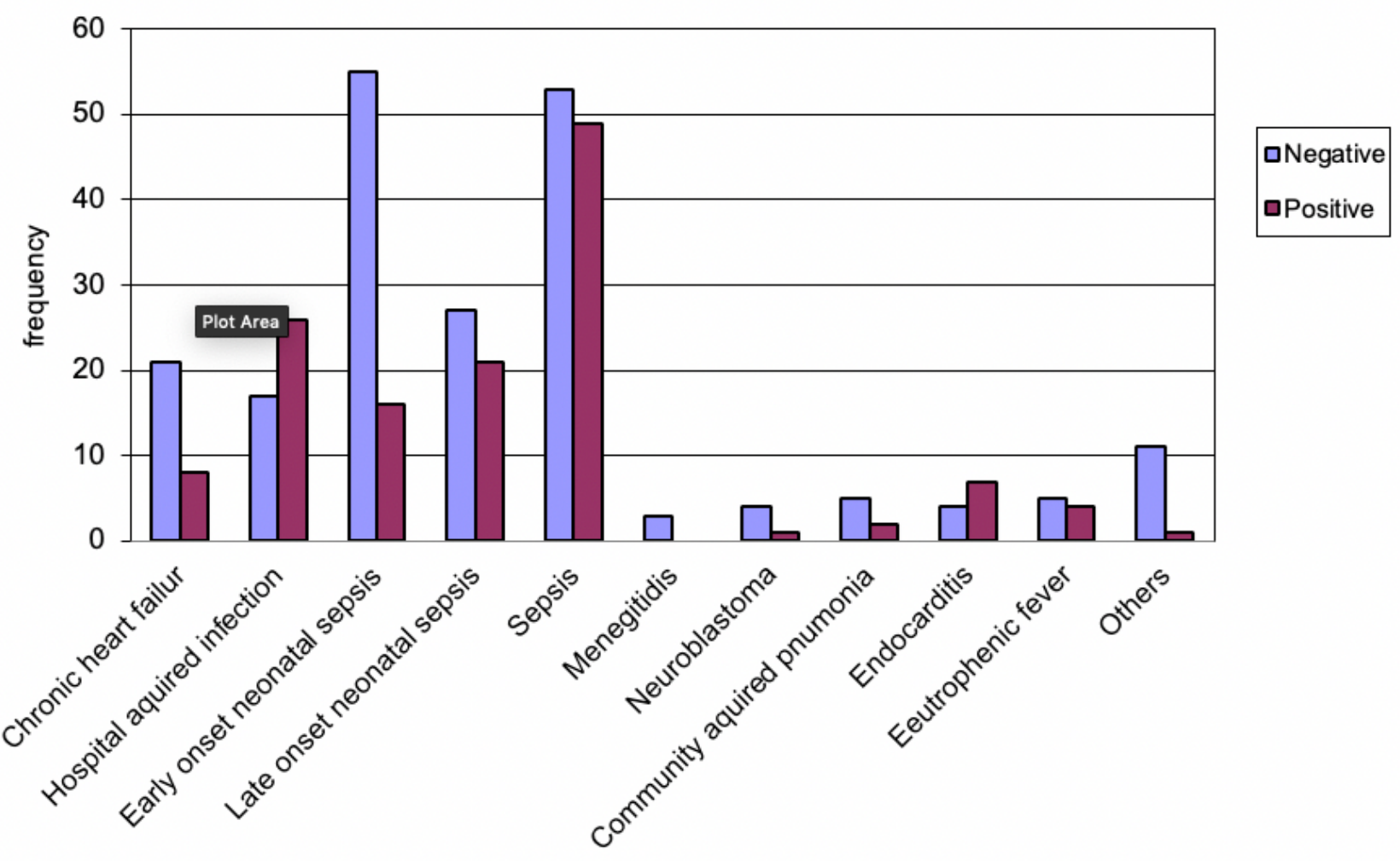

Figure 1

Distribution of clinical condition of patients among positive blood culture from blood stream infection suspected septicemia in Tikur Anbesa Specialized Hospital, 2018

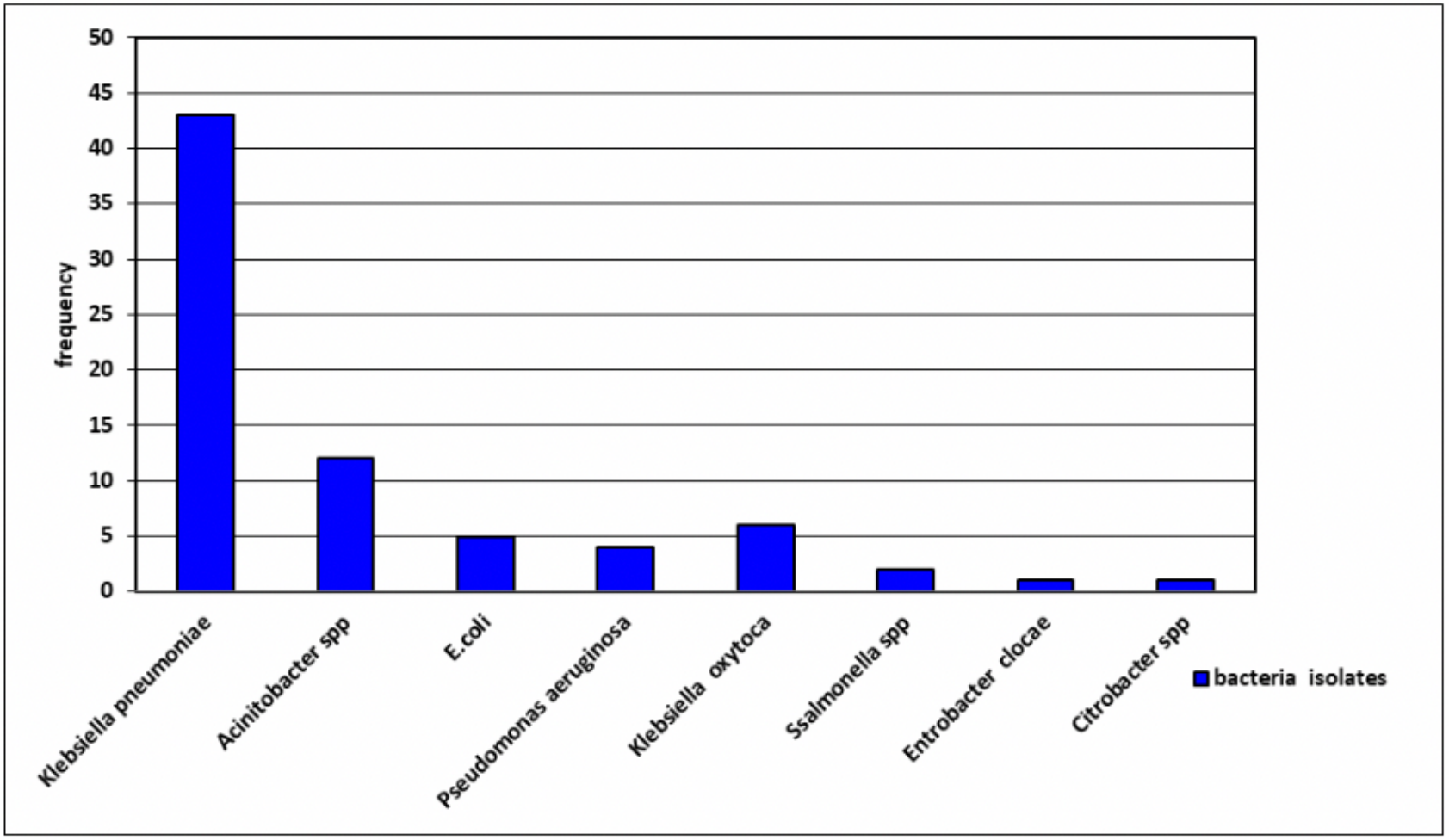

Figure 2 
Distribution of bacteria pathogens among positive blood culture isolated from blood stream infection suspected of septicemia patients in Tikur Anbesa Specialized Hospital, 2018

Page $14 / 14$ 